\title{
El discurso literario, propuesta teórica y sistematización: entre planos y voces
}

\author{
Literary discourse, theoretical \\ and systematization: between plans and voices
}

\author{
María-Pilar Suárez Pascual \\ Marta Tordesillas Colado \\ Universidad Autónoma de Madrid
}

\section{RESUMEN}

En estas páginas deseamos presentar un marco de análisis del discurso literario que pueda integrar las reflexiones - y las herramientas_-generadas en el terreno de la lingüística contemporánea. Para ello, partimos de la concepción del discurso literario como un discurso más, matizado si cabe por la explotación marcada de algunas dinámicas u objetivos específicos que nos llevan a designarlo como literario, al tiempo que le atribuimos la característica de ser un acto de lenguaje. A estos dos principios, le aplicamos la hipótesis esencial según la cual todo discurso presenta un tejido semántico fundamentado por una configuración lingüística que combina cuatro planos fundamentales: tópico, enunciativo, argumentativo y locutivo. Asimismo, y con el fin de generar un marco de trabajo más amplio, hemos incorporado el plano del imaginario en tanto que perspectiva que sitúa al discurso literario, al discurso en general, en un contexto antropológico y discursivo que permite profundizar en rasgos y mecanismos de su configuración. Este planteamiento teórico se ve acompañado, a modo de ilustración, de una aplicación a Las Coplas a la Muerte de su padre de Jorge Manrique.

Palabras Clave: Discurso literario, enunciación, argumentación, imaginario.

\begin{abstract}
In these pages we present a framework for analysis of literary discourse that may include consideration-and tools-generated in the field of contemporary linguistics. We start from the conception of literary discourse as a discourse, if it qualified for the operation marked some dynamics or specific goals that lead us to designate it as literature, while we attribute the characteristic of being an act of language. These two principles, we apply the essential assumption according to which each has a web address for a configuration based semantic language that combines four fundamental levels: topical, expository, argumentative and locutionary. And to generate a broader framework, we have incorporated the plane of the imaginary, as a perspective that places de literary discourse, the discourse en general, in an anthropological and discursive context that allows further features and mechanisms configuration. This theoretical approach is accompanied by an application to Las Coplas a la Muerte de su padre by Jorge Manrique.
\end{abstract}

Key words: Literary discourse, Enunciation, Argumentation, Imaginary. 


\section{APROXIMACIÓN AL DISCURSO LITERARIO}

El discurso literario es un acto de lenguaje general (desde la escenificación del lenguaje/lengua) y particular (desde la escenificación de la lengua/ discurso) en que se desarrollan las posibilidades que la lengua ofrece. El locutor, figura del discurso, pone en juego una serie de instrumentos linguiísticos y mecanismos paralingüísticos que están a su alcance, a partir de cuya gestión y tensión (García Negroni, M.; Tordesillas, 2001), el discurso tiene la capacidad de crear sentido enmarcado en una enunciación y argumentación y vinculado a un contexto concreto sociocultural más amplio. El resultado de esta actividad es un conjunto de marcas y estrategias discursivas mostradas y constitutivas que se le ofrecen al lector (posible interlocutor presupuesto por dicho acto de lenguaje) y a las que éste habrá de acceder siguiendo las instrucciones inscritas en el discurso que el autor/locutor, en mayor o menor grado de conciencia, y en interacción con la lengua, ha ido dejando en su obra. Dichas marcas son susceptibles de convivir con las instrucciones de orden contextual cuya identificación por parte del lector será oportuna con el fin de contribuir a desvelar con precisión esos efectos de sentido que la obra ofrece.

Desde estos planteamientos, algunos de los presupuestos de las ciencias del lenguaje son de gran ayuda para llevar a cabo un estudio completo de la obra literaria. Nos apoyaremos en distintos conceptos que emanan de este campo en la medida en que nos permiten una aproximación y descripción sistemática, profunda y amplia del hecho literario, que se verá complementada al integrarse con nociones procedentes de otras ciencias humanas - historia, antropología, sociología, etc.- que permitirá profundizar en su dimensión contextual ${ }^{1}$.

Los más recientes desarrollos en semántica y pragmática se revelan como una vía de análisis completo del fenómeno de creación especialmente en las cuestiones siguientes:

- Distinción de los planos implícito y explícito; el tejido y las partes que los conforma, la oración y el enunciado y, por ende, los sustratos del significado y del sentido. Para llevar a cabo este recorrido, resulta de utilidad la noción de signo discursivo (Tordesillas, 2008, 2002).

- La configuración interna y externa del discurso ya sea en su configuración enunciativa y locutiva, en su configuración tópica y argumentativa (Tordesillas, 2004, 2007); así como el papel de la actividad enunciativa en la arquitectura lingüística en el mundo que construye ${ }^{2}$.

${ }^{1}$ En este sentido no podemos dejar de señalar estudios y autores que han desarrollado una línea cercana de trabajo imbricada en los estudios lingüísticos y planteados desde una perspectiva englobante: Yllera, (1974, 1999); García Berrio, 1994; Garrido Gallardo, (1994, 2010); Del Prado, 2004; Moeschler \& Reboul, 1998; Forget, 2000.

${ }^{2}$ Es importante destacar la relación que mantiene el locutor con los enunciadores y con los puntos de vista. Cf. (Tordesillas, 1997; Suárez, 2010). 
- La constatación de que numerosos enunciados tienen la propiedad de presuponer e implicar otros enunciados a los que se accede mediante un procedimiento de presuposición e inferencia, presente e inscrito de manera más o menos transparente y accesible en la propia configuración lingüística, susceptible de comportar datos contextuales socioculturales e ideológicos (Suárez, 2002).

En esa misma línea, planteamos una semántica y una pragmática que contemplan la enunciación y la argumentación como los vectores lingüísticos principales inscritos en la lengua y la enunciación, principios particulares mediante los cuales el locutor convoca a un/os enunciador/es y unos topö̈, desencadenantes y transcendidos por un «objetivo» y una «mirada» que llevará a que el significado cristalice en el sentido. Este, por su parte, sólo se actualiza considerando las condiciones de su enunciación -los interlocutores, la situación de enunciación y las condiciones espacio-temporales-. El sentido será entonces un tejido que comporta un conjunto de instrucciones lingüísticas y contextuales que permiten acceder al significado del enunciado.

\subsection{Obra literaria-Discurso literario}

Entendemos, entonces, la obra literaria como un discurso, como un tejido de significación, entidad de sentido global, compuesta por diferentes dinámicas discursivas articuladas, en las que, a su vez, se combinan la enunciación y la argumentación, implícita y explícita, vehiculadas por una serie de presupuestos, inferencias, palabras, enunciados, o signos discursivos: todo ello posee una cohesión y una coherencia internas en las que está presente la actividad que el locutor imprime en dicho conjunto. Así, resultará esclarecedor para su comprensión la consideración de, por lo menos, los fenómenos siguientes:

- la identificación y segmentación del discurso. El proceso de identificación y segmentación se realizará desde el punto de vista semántico, es decir que las delimitaciones entre los distintos planos y/o niveles se llevará a cabo a partir de las identificaciones de unidades de sentido más o menos amplias. Así nos detendremos en el discurso en su globalidad, en cada uno de sus planos y/o niveles discursivos hasta llegar a la palabra; o bien trazando el recorrido en sentido inverso: de la palabra hasta sus discursos posibles. Podremos recorrer dos caminos principales: ir del macrodiscurso al microdiscusro o actuar en sentido inverso.

- la progresión discursiva. Todo discurso se desarrolla como tal en virtud de un sentido global que coincide o no con el sentido particular de sus unidades, de planos y/o niveles. El sentido general del discur- 
so se produce porque las unidades semánticas del discurso progresan, se despliegan.

- la articulación discursiva. Las diferentes unidades y/o planos semánticos se enlazan entre sí y con el contexto mediante diferentes procesos que llamaremos tensión, gestión, coherencia y cohesión.

\subsection{En torno a la enunciación}

Un rasgo característico del discurso, y trascendente en la lengua, son las marcas de enunciación como puntos de emergencia de una instancia de subjetividad que enuncia mediante recursos y actos que, en este caso, persiguen, se le supone, fundamentalmente la creación literaria. La manera en la que el locutor gestiona las posibilidades que la lengua le ofrece — selección del material, su organización, mayor o menor grado de adhesión o distanciamiento-, así como la manera de implicar o invocar al interlocutor (lector) son pistas que éste ha de seguir para extraer con éxito dicho sentido sin forzar el proceso de lectura. Al hilo de esta cuestión señalaremos que dichas marcas están referidas a aquella figura que a la que el discurso atribuye la responsabilidad de la enunciación, el locutor, instancia que no tiene porqué coincidir con el autor. Resulta clave en este sentido el principio científico relativo al concepto de polifonía enunciativa, propuesto originariamente por Ducrot (1984a), aunque, en otros términos, ya lo encontramos en Bakhtine. Se trata de concebir el sentido del enunciado como una escena de teatro en la que se establecen figuras discursivas, así el locutor y enunciadores, que cristalizan en el sentido en el que se genera una polifonía enunciativa. Si Bakhtine lo aplica al texto, la originalidad de Ducrot será aplicarlo al sentido mismo del enunciado. La noción de polifonía no sólo nos sitúa ante la existencia de diversas voces dentro de un mismo enunciado, sino que nos permite, por ende, concebir el discurso literario como entramado de perspectivas y puntos de vista que concierne a los distintos planos/niveles semántico y pragmático que se producen dentro del propio discurso, al juego que se genera entre el locutor, los enunciados y los puntos de vista, entre narrador, personajes y perspectivas, o al intercambio, no siempre explícito, entre el locutor y un interlocutor presupuesto, así como, en su caso, entre un narrador y un narratario presupuesto.

\subsection{En torno a la argumentación}

La argumentación, junto con la enunciación es un plano capital que teje el sentido de la lengua y, por ende, la configuración semántico pragmática del discurso. Entendemos que la argumentación se halla inscrita en la propia len- 
gua (Ducrot, 1984b), en el léxico, en el enunciado, en el discurso y constituye un plano que dirige y asegura la discursividad. En su circunscripción lingüística más intrínseca conlleva rasgos como la nocionalización, la orientación, la «guionización», la proyección y desarrollo de lugares comunes discursivos que se trazan desde y mediante los topoï, los garantes, las variables y dinámicas argumentativas y la estrategia inscritos en el discurso. Los citados elementos están y permanecen en el discurso, y resultan accesibles desde las huellas discursivas, que desencadenan a su vez instrucciones que permiten dibujar la configuración discursiva tanto desde el discurso hacia la lengua, como del discurso hacia el contexto y ello en una doble dimensión de lo implícito y lo explícito, y en esa doble faceta de interacción semántico pragmática.

\subsection{La dimensión contextual}

Otro aspecto que nos resulta de gran interés en el ámbito de los estudios de semántica y de pragmática es la posibilidad que su aparato conceptual nos ofrece de integrar en un trabajo descriptivo del discurso la vertiente contextual, tanto perteneciente al ámbito intradiscursivo, como al orden extradiscursivo. El estudio de dicha vertiente nos proporciona pautas y conocimiento para determinadas fases de la comprensión del discurso y, en particular, para su interpretación en un marco contextual complejo que, en una u otra medida, se hace presente en el sentido del discurso. La integración de los datos lingüísticos con los datos contextuales permitirá obtener resultados de gran valor significativo, desde el momento en que se podrá observar el discurso en su mayor amplitud semántico pragmática que irá tanto desde la posibilidad del sentido de su producción y confección hasta la posibilidad del sentido de su comprensión e interpretación. En este caso y con la voluntad de dar cuenta del contexto y de su situación socio-espacio-temporal, que no sólo se circunscribe al tiempo y al espacio, sino también al marco social entendiéndolo como integrador de un estado cultural, científico e ideológico, llevaremos a cabo una descripción pormenorizada de posibles presupuestos o vínculos antropológicos, históricos, enciclopédicos, así como de los posibles interlocutores de la obra. Una vez establecido el marco veremos en qué medida el contexto ya está inscrito, explícita o implícitamente, en el discurso y en qué medida se puede inscribir para un mejor reconocimiento del sentido de éste.

\section{LA DESCRIPCIÓN DEL SENTIDO}

Los fenómenos a los que nos hemos venido refiriendo ponen de manifiesto el contenido potencial, complejo y heterogéneo del tejido del discurso litera- 
rio en sí mismo y por otro lado, la fundamentación e inscripción de dichos aspectos en la configuración lingüística. Para abordar este entramado y descubrir la configuración semántica del discurso, la primera de las tareas necesarias es la de identificar, localizar y analizar lo que «el discurso nos dice de sí mismo».

\subsection{Los planos del discurso}

El principio que supone considerar la obra literaria como una producción discursiva entraña, desde esta perspectiva, plantear la obra literaria como un principio de interacción sociocultural, ideológica e intersubjetiva procedente de una conformación y/o confrontación emocional-racional que se traduce en una aprehensión y selección enunciativo-argumentativa de las que dan cuenta un sistema léxico, y de dinámicas y variables determinadas con proyección discursiva. Este material, aunque susceptible de ser ilimitado en su combinación y gestión, queda determinado en el propio sentido del discurso, en su tensión más intrínseca. Desde el momento en que otorgamos a la configuración lingüística un papel crucial en el estudio del discurso literario, conviene que especifiquemos lo que entendemos por configuración lingüística y para ello lo primero que debemos definir es el concepto de lengua y de configuración lingüística que planteamos. Las hipótesis que formulamos en este sentido son:

- La lengua es un sistema dinámico en el que los elementos que lo conforman son instancias discursivas interactivas, predefinidas por su significado que cobran cuerpo en una forma de extensión variable, de donde diremos que la lengua es discurso y que detrás de cada extensión se instauran discursos posibles. Para su observación requerimos, desde el punto de vista metodológico, una serie de instrumentos descriptivos.

- Toda configuración lingüística es una interacción significativa que comporta un tejido organizado intrínsecamente e interrelacionado. Lo trataremos metodológicamente, al principio a partir de cuatro planos fundamentales: el plano tópico, el plano enunciativo, el plano argumentativo y el plano locutivo, a cuya consideración añadiremos posteriormente el plano del imaginario. Los citados planos constituyen el fundamento sobre el que se teje el discurso y consideraremos que cada uno de ellos está compuesto por una serie de elementos e instrumentos que a continuación expondremos brevemente.

- Puesto que han sido tratados en publicaciones previas, nos permitiremos esbozar los ejes esenciales que dan sentido y cuerpo a cada plano y a su concepción. Así, diremos que el eje enunciativo tiene que ver con la enunciación y más concretamente con todos aquellos fenómenos relacionados con las figuras discursivas y sus funciones, papeles y participación en el discurso. Este plano comporta el estudio y análisis del escenario enunciativo, sus figuras discursivas, sus relacio- 
nes y sus actuaciones. En el plano tópico se produce todo aquello que tienen que ver con la aprehensión espacio-temporal de la situación y el posicionamiento y perspectiva desde la cual se proyecta el discurso: se atenderá por ejemplo a la orientación, proyección, gradualidad, etc... El plano argumentativo cobra sentido en relación con aquellos lugares comunes y garantes que aseguran y posibilitan la coherencia y cohesión del discurso, para terminar con el plano locutivo que se concibe como aquel donde se dan cita los objetivos del discurso, así como los términos y figuras que favorecen que llegue a término un proyecto discursivo. Lo concretaremos como sigue:

\begin{tabular}{|l|l|l|l|}
\hline \multicolumn{1}{|c|}{ TÓPICO } & \multicolumn{1}{c|}{ ENUNCIATIVO } & \multicolumn{1}{c|}{ ARGUMENTATIVO } & \multicolumn{1}{c|}{ LOCUTIVO } \\
\hline - noción:+/-/ф & - punto de vista & - topos & - aprehensión ego, hic et nunc \\
- orientación & - enunciador & - garante & - selección \\
- guión & - locutor & - variables argumentativas & - empleo/uso \\
- proyección & - mirada & - Dinámicas argumentativas & - tensión \\
- desarrollo & - objetivo & - estrategia & - gestión \\
\hline
\end{tabular}

Insistimos en que los planos interactúan, de modo constante entre sí, al igual que lo hacen sus respectivos componentes de modo a desarrollar la tensión y asegurar la gestión del discurso y ello mediante las actividades siguientes.

1) Plano DE LA TOPICALIDAD

Actuación

— intersubjetividad/interrelación

— inserción

- conciencia/ inteligencia

— voluntad/decisión

- necesidad

- progreso/desarrollo

Calificación

- aprehensión

- atribución $+/-/ \phi$

- nocionalización / escala de la nocionalización

— grado de calificación

- orientación

- lexicalización

Despliegue de la calificación

- guion

- componentes tópicos

- escala tópica 
- grado tópico

- variables discursivas

- orientación de las variables

- papel/función

- enunciado

2) Plano de LA ENUNCIACIÓN

Escena enunciativa

- participantes

- sujeto de la enunciación

- objetivo de la enunciación

- situación de enunciación

- modalidades de la enunciación

— índices de persona/ indicadores de opinión

La polifonía y la poliacroasis

- polifonía constitutiva/polifonía mostrada

— papeles de las figuras discursivas/ relación entre ellas.

$\mathrm{Marco} / \mathrm{s}$ discursivo/s

- aprehensión argumentativa

- transparencia de la enunciación

- actos de habla

- ironía

Palabras o expresiones que comportan la intersubjetividad

- términos con valor expresivo

- empleo de connotaciones

- términos con valor de imagen

- adjetivación

- adverbialización deíctica

Soporte discursivo

- el terreno de lo explícito y el de lo implícito

- escritura y oralidad

- dimensión, extensión y desarrollo del objetivo en el discurso

- formas de las funciones del soporte

3) Plano DE LA ARGUMENTACión

Redes y campos léxicos

- localizar la/las red/es léxica/s

- localizar el/los campo/s léxico/s

- relaciones entre campos léxicos

Estudiar el sentido de una palabra, de una expresión o de un enunciado

- polisemia, sinonimia, antonimia, etc.

- sentido etimológico/ sentido histórico/ sentido figurado 
El discurso de la palabra

- orientación de la palabra

- lugares comunes, topoi, estereotipos

- garante argumentativo

Tesis, argumentos, ejemplos

— argumentos y ejemplos

- silogismo y entimema

- estudio de la progresión argumentativa

Tipos de razonamiento

— inductivo/ deductivo

- causal/ concesivo

- hipotético

- crítico

- por el absurdo

Relaciones y conectores:

— instrucciones argumentativas

- puntuación

- yuxtaposición

— Índices temporales

4) Plano de la LOCUCiÓN

La corporeidad del ethos

- tono

— expresión: claridad, corrección, ritmo/códigos paralingüísticos/ códigos no-lingüísticos

- estilos (genera elocutionis)

- cooperación e interacción

- ethos y pathos (el juego de la emoción)

Partes del discurso:

- compartimentación tradicional: exordio/narración/demostración/epí$\log 0$

- modos del desarrollo del discurso: intellectio, inventio, dispositio, elocutio, memoria, actio, pronuntiatio.

- progresión y orden: ordo naturalis/ordo artificialis.

- composición: coordinación, subordinación/ redundancias y recurrencias.

Dinámicas retóricas:

- analogía/ oposición

— amplificación/ atenuación/ contención

— síntesis/ disjunción

— adhesión/ retractación

- sustitución 
Géneros:

- de los genera a los géneros literarios/géneros del discurso

- la Intertextualidad

\subsection{El plano del imaginario}

Acabamos de presentar la literatura como hecho lingüístico, asociando al acontecimiento discursivo un carácter también estético donde entran en juego los factores de lo humano. En tanto que hecho estético que se desarrolla en una zona donde descienden las constricciones impuestas por el plano de lo inmanente, la literatura es un terreno privilegiado de la imaginación, término este último a menudo asociado con «fabulaciones vacías». Ahora bien, cuando hablamos de imaginación lo hacemos en el sentido de actividad que genera imágenes. La imagen es un instrumento que permite llevar a cabo una objetivación/canalización de la energía psíquica vinculándola a una figura sensible, y cuya realización es susceptible de cristalizar en una expresión, ya sea plástica o lingüística.

Particularizando en el ámbito del discurso entendemos por imagen -imagen discursiva - una construcción en la que una energía psico-sensorial cobra cuerpo, de modo figurado, en su vinculación con una construcción procedente del discurso, tejiéndose en la interacción con la lengua y su ejercicio.

Gran parte de las investigaciones en el terreno del imaginario fueron llevadas a cabo por el antropólogo francés Gilbert Durand $(1969 ; 1996)$ quien definía la imagen en virtud del aspecto figurado del significante, y considerando que dicho significante era el medio más eficaz para dar a conocer el significado, al cual, por otra parte, resultaba difícil de acceder de modo directo. Imágenes que constituyen redes funcionales, que se organizan en campos orientados por objetivos afectivos y se gestan en el transcurso de un «trayecto antropológico» (Durand, 1969: 123). A partir de esos parámetros, Durand propone una organización de las imágenes en constelaciones, y éstas las contextualiza en una articulación más general a la que denomina régimen. Se constituye así un marco donde es posible observar la dinámica de gestación de las imágenes y los funcionamientos a los que da lugar su semantismo. Algunos de estos planteamientos nos resultan de especial interés en tanto que nos ofrecen una perspectiva que permite vincular el discurso en su gestación y desarrollo, con un contexto antropológico/biológico y con un contexto cultural.

Las imágenes presuponen un lenguaje, en el caso que nos ocupa la lengua natural. Si bien en el momento en que formula estas teorías son formuladas - los años sesenta-, se opone el concepto de imagen al de signo lingüístico, también es cierto que dicha oposición es planteada desde la concepción 
de signo vigente en los años sesenta, la cual ha venido siendo revisada en las últimas décadas.

Así, desde la propuesta lingüística que hemos venido presentando en páginas anteriores, que considera que la lengua es discurso que comporta emoción, que integra lo consciente y lo inconsciente; la afectividad, la sensación, la ideología, la necesidad, etc. podemos pensar en considerar el plano del imaginario como un componente susceptible de interactuar y de intervenir en la construcción de la arquitectura del discurso en general, - $-\mathrm{y}$ del literario en particular-, que lo trasciende, y encuentra sus puntos de vinculación con los otros planos anteriormente expuestos (Suárez, 2007: 309)

Planteamos, pues, en lo que al discurso se refiere, la imagen en tanto que resultado sensible, figurado, de una condensación emocional y socio-ideológica, que comporta un componente histórico y diacrónico. Su sentido se configura en el marco de una topología de constelaciones de imágenes y en virtud de una serie de miradas y posiciones, con las que, en mayor o menor medida, se relaciona o asume quien, en un momento preciso, las desarrolla o elabora. Por otra parte, teniendo en cuenta una concepción polifónica de la lengua, en la arquitectura del discurso —nos atreveríamos a decir de todo discurso- - la imagen, al igual que el discurso, o la palabra, es imagen de imágenes, esto es, las imágenes que articulan un discurso se hallan influidas por otras imágenes y por los diversos puntos de vista que han podido intervenir en su construcción.

La producción de imágenes resulta propia del ser humano, y característica de la manera en que se va construyendo su vida, su historia, su entorno, en definitiva su cultura y, por ende, los discursos. Consideramos pues que en todo discurso se hallan presentes (explícita o implícitamente) trazos del posicionamiento y la aprehensión del ser humano con respecto a su cultura, a su aquí y ahora: ahí se hallaría ese plano del imaginario, que cobra cuerpo en la aprehensión/enunciación de relaciones y tensiones, y que se hace patente tanto en las opciones y discursos más aparentemente banales y cotidianos, como en la más fantástica de las ensoñaciones.

Desde estos planteamientos, pensamos que la aproximación a esta configuración permite profundizar en las redes de sentido sobre las que se asienta y se desarrolla el discurso, en su gestación y progresión, lo que podría contribuir a ayudar a descifrar implícitos y sobreentendidos: a dar cuenta de un universo de sentido interno al discurso. El imaginario se hace eco de la subjetividad enunciativa del yo que enuncia y se enuncia; del marco en el que se inscribe, de su aprehensión del espacio y el tiempo, del modo de aprehender sus puntos de anclaje con el mundo, y la forma de construirlo y construirse frente a éste.

A partir de los conceptos que acabamos de mencionar, apuntamos un esquema que, a nuestro juicio, puede dar cuenta de este plano: 


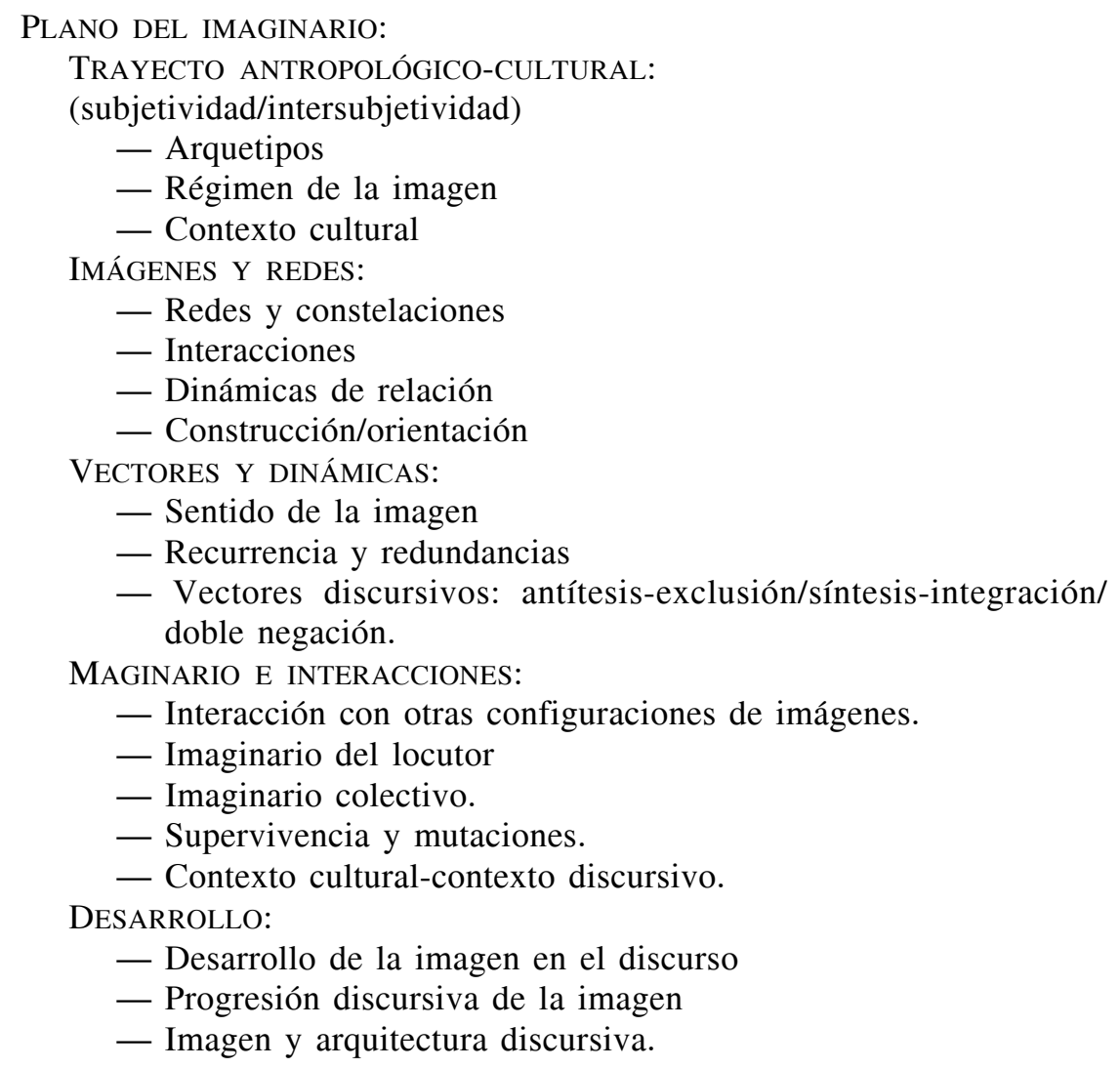

Insistiremos en este punto en que los conceptos utilizados anteriormente tienen que ver con una concepción de la lengua vinculada a un principio de actividad, de dinámica que formula como principal hipótesis el sentido en términos argumentativos y enunciativos.

Estas propuestas permiten emprender un trabajo que consistiría en detectar aquellas imágenes sobre las que se articula el discurso, y su vinculación con los núcleos de sentido y vectores semánticos que determinan su configuración y progresión. La topología de imágenes a la que anteriormente nos hemos referido nos ofrece la posibilidad de llevar a cabo una contextualización en un marco formado por un vasto entramado discursivo antropológico y cultural, al que, por otra parte sólo podemos acceder desde el propio discurso y mediante el material lingüístico explícito que éste comporta.

La opción léxica es quizá uno de los puntos donde, tal vez, con más evidencia se deja ver este aspecto; el cual cobra asimismo cuerpo en el juego y la articulación de voces que confluyen en el discurso: nos podemos interrogar sobre el régimen de la imagen que rige los enunciados y observar el modo 
en que ello incide en la perspectiva atribuida y atribuible a cada uno de los participantes y figuras que forman parte del proceso de la enunciación. En efecto, las constantes que se advierten en la producción de imágenes de un discurso o de una comunidad lingüística, se hacen también patentes en la aprehensión del yo frente al tú; o del tú frente al yo. Y todo este dispositivo influye en la arquitectura del discurso con vistas a expresar, modular o generar una serie de emociones deseadas y previstas en mayor o menor grado.

Desde ahí podemos asimismo dar cuenta de configuraciones discursivas de amplitud variable — tipos, motivos - de la misma manera que podemos ahondar en los topoï, o garantes implícitos que emanan de un universo semántico concreto del discurso, y que permiten el desarrollo argumentativo de éste. Igualmente entendemos que esta perspectiva, que ha ido influyendo en la orientación de las construcciones particulares del mundo, tiene trascendencia en la elaboración de las figuras retóricas, así como en la articulación y relaciones que median entre los distintos núcleos semánticos sobre los que el discurso se asienta. Las dinámicas más o menos recurrentes de oposición/exclusión, integración/causalidad, doble negación... de las que darían cuenta los distintos marcadores se hallan, a nuestro juicio, relacionados con el tejido semántico del discurso.

A modo de síntesis, proponemos igualmente el cuadro siguiente, en el que la dimensión lingüística aparece recogida en sus diferentes planos ${ }^{3}$, y enmarcada en una reflexión que se apoya en un entramado de perspectivas científicas adaptadas a las hipótesis científicas contemporáneas. (cuadro pág. 24). La interrelación que media entre los diferentes planos que formulamos - pese a su explicitación en terrenos independientes-, y la integración de disciplinas y perspectivas diversas que establecemos, ofrece la posibilidad de estudiar, de manera integral, el fenómeno complejo que es el discurso en general, así como la obra literaria en particular. El esquema permite por otra parte abordar el texto en un aspecto concreto del mismo, ofreciendo a la vez la posibilidad de enmarcar dicho análisis dentro de la configuración discursiva, en su totalidad y su complejidad.

\footnotetext{
${ }^{3}$ Venimos trabajando en diversas propuestas de análisis del texto y/o discurso literario desde 1988. Por un lado, los 4 planos del discurso que figuran en páginas anteriores fueron planteados por Tordesillas, en 1998, en Reims, en el VI Congreso internacional de Pragmática, en su intervención «Les connecteurs: sémantique et pragmatique» y en «Esbozo de un marco teórico en lingüística para el análisis del discurso» en el V Congreso Internacional de Lingüística Francesa celebrado en Lérida en 2001 Cf. Tordesillas, 2001, 2004, 2005, 2008. Por su parte, Suárez ha venido publicando trabajos en el campo de la literatura desde la integración de perspectivas que emanan del campo de la lingüística y del de la antropología cultural (cf. Suárez, 1998, 2002, 2004, 2007, 2012). Una exposición teórica más definitiva de los 5 planos, que reformula el cuarto plano e incluye el quinto tal y como lo hemos desarrollado en el presente artículo, fue concebido por Suárez y Tordesillas, en 2008 y expuesto en el IX Congreso Internacional de Lingüística Francesa, celebrado en la UAM en el mes de noviembre de 2010.
} 


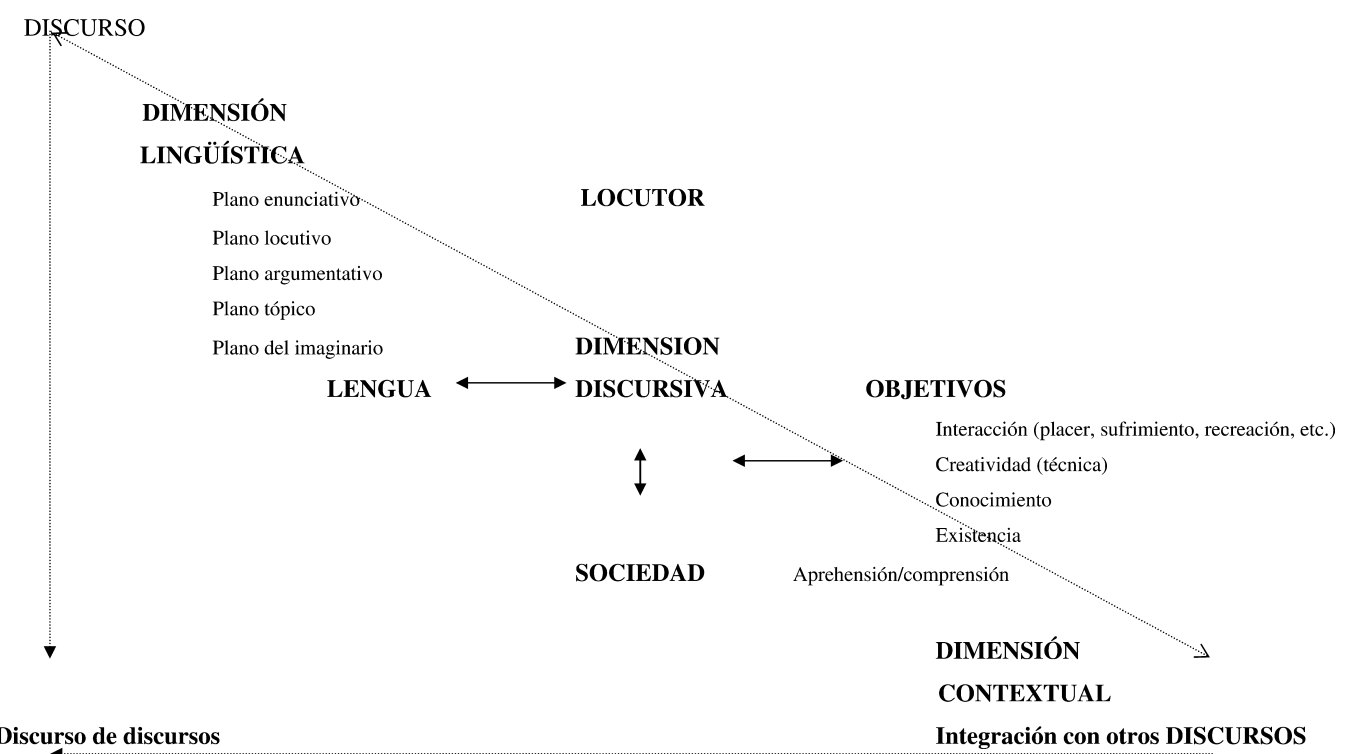

\section{Una aproximación a las Coplas a la MUERTE de su Padre de Jorge MANRIQUE}

Con el fin de ilustrar el funcionamiento del marco teórico propuesto que acabamos de referir, junto con trabajos anteriores los que hemos ido dando cuenta a lo largo del artículo, proponemos el acercamiento a un discurso literario: Las Coplas a la Muerte de su Padre de Jorge Manrique ${ }^{4}$. Suficientemente conocido para que nuestra propuesta adquiera una dimensión de intercambio dialógico, el que no sea una obra demasiado extensa permite ofrecer una mirada de conjunto sobre ella evitando el peligro de las ilustraciones fragmentarias. A lo largo de este trayecto, y teniendo en cuenta la delimitación formal que impone el espacio, destacaremos los fenómenos constitutivos fundamentales, vinculados a cada uno de los planos. En algunos casos retomaremos algunas secuencias discursivas, para abordarlas desde planos diferentes: desde miradas que convergen y se complementan mostrando así la coherencia del tejido semántico y pragmático que conforma las Coplas.

${ }^{4}$ La muerte de Don Rodrigo Manrique tuvo lugar en 1476: casi todos los editores de su obra sitúan la composición del poema en 1477, pese a que hay hipótesis que sostienen que parte de la obra pudo ser escrita con posterioridad a ésta. Para profundizar más sobre la obra de Manrique, en especial las Coplas, remitimos a los estudios y ediciones de los que han sido objeto, algunas de las cuales detallamos en la bibliografía. Por nuestra parte hemos seguido la edición de Jesús-Manuel Alda Tesán (Manrique, 1992). 
Por una cuestión práctica comenzaremos por los planos enunciativo y argumentativo buscando como punto nuclear marcas del locutor, y el modo en que éste va creando hechos, personajes y situaciones, posicionándose ante ellos. En un segundo momento, pasaremos al plano argumentativo con el fin de estudiar los núcleos a partir de los cuales se establece la progresión del discurso, para a continuación, observar la perspectiva y el contexto cultural y antropológico desde la cual éstos se han venido configurando — plano del imaginario. Después abordaremos el discurso en su corporeidad - plano locutivo-, y finalmente el modo en que se produce el desarrollo discursivo general (plano de la topicalidad).

\subsection{Plano de la enunciación}

Comenzaremos proponiendo una segmentación, atendiendo para ello a la deixis enunciativa en su vínculo con el propio acto discursivo y con la temática aludida. En este proceso observamos un locutor a menudo identificado con la primera persona del plural, así como una tercera persona «impersonal», que permite convocar diferentes voces virtuales, a las que da curso en el poema modo de enunciadores. Son bases para la composición de las distintas escenas enunciativas.

El locutor, desde esa primera persona del plural, interpela a una parte de sí, o a la «sociedad» de su tiempo sobre el paso del tiempo y la muerte. Y se muestra en distintos momentos del poema como yo poeta/autor, ser del mundo, que habla sobre su acontecer discursivo a través de un explícito «digo» (IX), o en un metadiscurso (IV) en el que indica cuál es su garante discursivo. Igualmente advertimos otros recursos como exclamaciones e interrogaciones retóricas que buscan la implicación de un interlocutor. Al final del poema cederá la palabra a otros locutores: la Muerte y el Maestre. Este último interviene en lo que es una respuesta a la muerte, que podría tener el valor de un monólogo interior — toma de resolución_, para a continuación instituir a Jesús, anteriormente convocado como garante, en interlocutor explícito a través de las marcas de segunda persona. En la estrofa final reaparece de modo explícito la voz del locutor principal que glosa la figura del personaje desde su adhesión a él, pero sin mencionar su condición de hijo, confiada al paratexto. En este marco enunciativo es preciso observar que tanto el título, como las indicaciones que preceden algunas de las estrofas IV: «invocación», XXXVIII: «responde el Maestre»; XXXIX: «Oración», orientan sobre la actividad enunciativa general, y contribuyen a definir la identidad de los distintos locutores. Así, el locutor principal es susceptible de ser asociado con el autor, y desde ahí, y a través del paratexto, establecer una relación de filiación con el personaje. Por otra parte Don Rodrigo es convocado en el discurso desde una faceta particular de su identidad: su dignidad de Maestre de la Orden de Calatrava. 
Teniendo en cuenta estas indicaciones básicas podemos trazar cuatro escenas enunciativas complejas, que comportan a su vez otros escenarios enunciativo-argumentativos que indicamos a continuación:

$1^{a}$ parte: I-XII (siendo la estrofa XII supuestamente apócrifa). En ella se advierte el posicionamiento y planteamiento enunciativo general, donde la muerte ya presente desde de la primera estrofa se constituye en vector directivo de la reflexión, mostrando su interacción dilemática con el otro gran vector, que es la vida eterna que a ésta sucede. Habíamos señalado al principio la dominante de marcas de la primera persona del plural que integra a locutor e interlocutor, y su alternancia con marcas de la tercera persona desde la que se constatan hechos para a continuación producirse un desplazamiento hacia la sentencia moral. Desde esta misma instancia el locutor conmina y exhorta $-3^{\text {a }}$ persona del imperativo. Desde la alternancia de constataciones, y de exclamaciones e interrogaciones retóricas — marcas explícitas de subjetividad - el locutor trata de instituir explícitamente a un interlocutor invitándolo a un posicionamiento frente a sus apreciaciones en torno a la vida y el tiempo. Tal sería el objetivo de la enunciación.

$2^{\mathrm{a}}$ parte: XIII-XXIV: Recorrido por personajes de la historia reciente del locutor y del personaje concernido, presidido nuevamente por la idea de la muerte: se advierte una progresión locutiva e interlocutiva, que va del «nosotros» (poeta/locutor/yo/interlocutor/nosotros) hacia el «tú» con que la muerte es interpelada (XIII-XIV). Como acabamos de indicar, media una red de interrogaciones y exclamaciones retóricas (qué, cómo, cuánto, dónde...), cuya opinión viene dada en esa misma formulación planteando un diálogo abierto con un «nosotros» (un «vosotros» presupuesto). La figura discursiva de la Muerte adquiere así un papel preponderante y casi atemporal en un discurso no exento de referencias históricas.

$3^{\mathrm{a}}$ parte: XXV-XXXII: tras este nuevo marco, se instaura un «yo» («quiero»-XXV) que mediante designación introduce al personaje del «maestre don Rodrigo Manrique» (XXV). A lo largo de la estrofa XXVI, continúa con 8 exclamaciones que ensalzan su figura a la vez que plantean el vosotros, ya generado en la segunda parte, a modo de interlocutor/lector, que continúa en las estrofas que siguen, XXVI-XXIX, desde la narración de personajes ilustres y sus hazañas famosas y favorables, para culminar, en la XXX y XXXI, con la alusión a algunos de los valores que los caracterizaron: «honra, estado, fechos famosos, victorias, habilidad, dignidad, fuerza». El «nosotros» es retomado en la estrofa XXXII «nuestro rey natural».

$4^{\mathrm{a}}$ parte: XXXIII-XL: en esta cuarta parte, se produce una corporeizacion del marco interlocutivo general. Recoge las voces que se han ido construyendo a lo largo del discurso y les da cuerpo lingüístico, mediante el discurso reproducido. El locutor cede la palabra a la Muerte y al Maestre. A través de un verbo dicendi, y al final de una proposición inaugurada en la estrofa anterior la Muerte hace su entrada en la escena enunciativa. Se trata del único 
encabalgamiento que detectamos en Las Coplas. Para introducir el discurso de don Rodrigo se recurre al paratexto — «Responde el Maestre ${ }^{5} »$, así como para mostrar el cambio de interlocutor — «Oración», término que presupone a Dios como interlocutor. Con este juego enunciativo se advierte la riqueza con que Manrique culmina su quehacer discursivo y, en cierto modo, vital. La voz de la Muerte es la instancia que permite la intervención directa de Don Rodrigo: «consiento en mi morir con voluntad plazentera, clara e pura» (XXXVIII), para, desde este consentimiento, dar entrada a la figura discursiva de Jesús, con un «Tú» (XXXIX. Este diálogo entre la Muerte, el Maestre y Jesús, se inserta, como discurso reproducido, en un marco enunciativo superior del «nosotros» («dexónos», XL), que reúne y en cierto modo concluye, tras un inciso del yo marcado entre paréntesis, las otras voces convocadas a lo largo del discurso.

\subsection{Plano de la argumentación}

Señalaremos así los elementos argumentativos clave, que no dejaremos de vincular con fenómenos inscritos en el plano enunciativo. Adelantaremos que el plano argumentativo avanza progresivamente fundamentándose tanto topoi como en dinámicas argumentativas y redes, en presupuestos e inferencias, así como en garantes, que van tomando forma a lo largo de las estrofas.

- I-XII: Las primeras estrofas sitúan al interlocutor ante el sentido mismo de la obra: el paso del tiempo y el grado de consciencia del hombre frente a ello. Interpelación formulada en tercera persona que se dirige en último término al «alma dormida», en dos de las potencias que la configuran — la memoria (recuerde) y el entendimiento (avive el seso). La voluntad será aludida al final del poema. Podríamos hablar de una interpelación sinecdóquica de éste, donde son convocadas distintas instancias que configuran el interior del hombre. Se trata de un juego en el que el hombre es mostrado en su pluralidad, en su condición polifónica a la que aludíamos al inicio de nuestra descripción, y cuyo punto de partida es la presuposición de una disociación, debida a lo que el locutor principal presenta como un estado de letargo. Es esa situación la que impide la convergencia de todas estas instancias para configurar una mirada consciente sobre la vida y el paso del tiempo, vinculado éste a la llegada de la muerte. El tiempo/espacio de la enunciación están inscritos en «este» mundo — presente- desde el que enuncia el paso hacia «aquel»/ «otro», generándose una bipartición en la que una alteridad - trascendente-

\footnotetext{
${ }^{5}$ Resulta por otra parte interesante notar que la identidad del personaje de Don Rodrigo se asimila a la dignidad más elevada que desde el punto de vista social - y moral - se le puede atribuir «por su gran habilidad, por méritos e ancianía bien gastada» XXXI. Una dignidad que recibió dos años antes de su muerte.
} 
es enunciada como positiva, explicitada en la invocación a Jesús (IV): «Aquél sólo invoco yo/ de verdad,/ que en este mundo viviendo/ el mundo non conoció/ su deidad», donde implícitamente se recoge la instancia joánica (inicio del Evangelio de San Juan).

«Aquél», referido a la instancia de lo Absoluto, se opone al determinante «este» referido a «mundo», para desde esa oposición instituir este último como tránsito con respecto hacia un orden superior previamente enunciado: «este mundo es el camino» (V)/ «este mundo bueno fue»(VI). Una correlación establecida mediante un argumento que podríamos denominar de «pertinencia»: «mas cumple tener buen tino»/ «si bien usásemos dél como debemos». Dicha correspondencia se ve asimismo reforzada mediante la presencia de verbos que expresan el desplazamiento y el tránsito —ir/venir; pasa/viene_-, modalizados por locuciones adverbiales «tan callando/cuán presto», que refuerzan la idea de movimiento tan rápido e inexorable, como inadvertido. Estas construcciones se hallan vinculadas a configuraciones léxicas, con un claro valor metafórico: «nuestras vidas son los ríos...», sobre las que volveremos más adelante.

La estrofa VII resulta un punto de inflexión en el juego enunciativo-argumentativo que estamos describiendo, pues introduce una situación que ilustra una toma de posición motivada por esa falta de perspectiva enunciada al inicio de la obra: se trata de la virtualidad de lo aparente. De este presupuesto parte el locutor para la construcción de su argumentación en las estrofas sucesivas que le permitirán dibujar contraejemplos con respecto a los cuales sitúa al personaje del Maestre. Se trata de una disyuntiva establecida a partir de la presentación de dos presupuestos contrarios: «si fuese en nuestro poder hazer la cara hermosa/como podemos hacer el alma». La dicotomía entre lo interno y lo externo da lugar a una subversión en la escala de valores con respecto a la cual el locutor se posiciona. El empleo de nosotros, situado frente a dos eventuales terceras personas — cara/alma—, remite de nuevo a un desdoblamiento sinecdóquico, en el que además confluye una personificación, que muestra una confluencia de instancias: esa naturaleza polifónica de la que dábamos cuenta al inicio de nuestra descripción, no siempre armónica, ni siempre ordenada, que forman parte del ser humano. La estrofa parece cambiar, o justificar el cambio, del tenor de los ejes: si en las primeras estrofas la vida es planteada en clave de paso que conduce a una alteridad superior, de la que anteriormente dábamos cuenta, a partir de VII se advierte la recurrencia de proposiciones construidas sobre la enumeración de seres, objetos y situaciones que son investidos por la finitud, en el marco del topos del ubi sunt. La pregunta es formulada desde el imperativo, y sin que desaparezcan las marcas de primera persona del plural, e incluso alguna ocurrencia del singular «pero digo» (XII) en una estrofa que los especialistas consideran apócrifa.

- XIII-XXIV: Este bloque abre una enumeración de lo perecedero expresada a través del artículo determinado, mostrado en redes semánticas 
construidas sobre un juego de inversiones que ya había sido esbozado en estrofas anteriores (IX): ligereza-pesadez// subir-bajar. Aparece de nuevo la dicotomía «esta/acá»-«allá». Ya no se trata de una alteridad enunciada como espacio eufórico, sino como espacio de la disolución de placeres y tiempos: placeres-acá (temporales)-tormentos-allá (eternales) (XIII). Cobra cuerpo un juego de metáforas que enuncia la vida como trampa (XIII) - la estrofa anterior la mostraba como «sueño» (XII). Se trata en todo caso de imágenes que convergen para llamar la atención del interlocutor sobre la mirada- «non MIRAR a nuestro daño» «desque vemos el engaño» (XIII)—, que confunde, que no está debidamente configurada. En una nueva intervención explícita del locutor éste determina la naturaleza de los garantes sobre los que articulará su argumentación (XV) «dexemos a los troyanos»/ «vengamos a lo ayer». Queda configurado el espacio y el tiempo de la enunciación, y de lo enunciado: personajes de la historia reciente del Locutor, y del personaje central, convocados desde la perspectiva de éste y su familia. Una enunciación construida sobre un saber compartido del mapa político de la época ${ }^{6}$. En este marco, son enumerados tipos y personajes de la corte a los que se atribuyen situaciones de poder (XVIII-XXV). Las estrofas muestran su unidad en torno a un tópico y a sus contradicciones internas: tematización de la finitud. De ahí la recurrencia de conectores concesivos del tipo «mas», o de interrogaciones retóricas construidas de acuerdo con la forma del ubi sunt: «qué fue de...» «fueron sino devaneos?», que producen un efecto de denegación del esplendor inicialmente enunciado.

Las dos últimas estrofas - XXIII/ XXIV - relanzan la argumentación desde una totalización — «tantos duques»—, recogiendo los argumentos anteriores para introducir al personaje de la muerte como interlocutor «tú», a través de una serie de imprecaciones que recuerdan su dimensión destructiva (claridad amatada; cruda/fuerza; airada/flecha). Esta configuración prepara el retrato del personaje principal, que a lo largo de varias estrofas va retomando los argumentos presentados en las estrofas anteriores para subvertirlos progresivamente.

- XXV-XXXII: Su presentación tiene lugar mediante un estilo anafórico que presupone un conocimiento previo por parte del interlocutor del objeto o persona convocada. Ello crea una suerte de clímax que precede la explicitación final de su nombre. El locutor — que en ningún momento se identifica explícitamente como hijo en el interior del discurso- reaparece en primera persona para justificar su silencio en función de esa presuposición — «sus hechos ya conocidos no cumple que los alabe». Sin embargo su declaración es sólo una preterición, ya que los versos que siguen no obedecen a otro propó-

\footnotetext{
${ }^{6}$ Rodrigo Manrique se rebeló contra Juan II, posteriormente contra Enrique IV, acordando su fidelidad al Infante don Alfonso. Más adelante se encontraría entre los partidarios de Isabel, contrarios a Juana, la hija y heredera de Enrique IV.
} 
sito que hablar de él. La etopeya tiene lugar mediante un proceso de concatenación de proposiciones exclamativas que recogen sustantivos muy marcados desde el punto de vista de la subjetividad de lo eufórico. Proposiciones cortas que contribuyen a crear una idea de saturación.

- XXVII-XXVIII: el locutor principal que en la estrofa XV expresaba su rechazo a convocar a los personajes de la Antigüedad como referentes, se servirá de algunos de ellos como puntos de comparación para enunciar las virtudes del Maestre, al que parece querer situar en el plano de «los héroes de antaño».

- En esta estrofa XXIX tiene lugar la negación de aquellos elementos enunciados como vacuos o perecederos en las estrofa anteriores: «grandes tesoros», seguida de un conector concesivo — «mas»— que introduce el rasgo que caracteriza al personaje descrito desde una relación de oposición con respecto a los personajes a los que anteriormente se ha hecho mención. Esto permite negar argumentos mostrados en las estrofas anteriores, construidos sobre el poder y las riquezas, y mostrar la progresión del personaje de Don Rodrigo desde una orientación distinta.

- Aquellos argumentos que, siendo atribuidos desde una perspectiva genérica a nobles, reyes, o personajes de la época, eran calificados como perecederos e inconstantes — por tanto no válidos-, son retomados desde una orientación positiva al serles atribuidos al Maestre: tierras (XXX) hazañas de su braço (XXXI), tierras-guerras (XXXII).

La construcción del personaje del Maestre se articula a partir de una argumentación a sensu contrario donde la guerra - contra moros y tiranosaparece como acción fundadora y donde la ganancia se revela como premio al esfuerzo. Es entonces cuando Fortuna no resulta adversa, la senectud no es agente de decadencia: estas «sus viejas estorias» son formuladas como un repertorio de hazañas renovadas, desde una perspectiva de duratividad implícita que se traduce en una regeneración dentro de la vida mortal. La vejez aparece por tanto para el personaje como lugar donde el triunfo se consolida y pervive deteniendo la mano destructora del Tiempo, que se ve para él atenuado: se rompe la redundancia obsesiva del ubi sunt.

— XXXIII-LX: La Muerte hasta entonces asimilada al «Juicio Divinal», aparece en estas estrofas instituida en Locutor (locutor 2) que se dirige al Maestre desde el «vos» la única ocurrencia en toda la obra, en un discurso respetuoso y benigno donde reconoce su excelencia, retomando los argumentos sostenidos por el Locutor principal en la primera parte: «este mundo es el camino/para el otro que es morada sin pesar»(V), y de los que Don Rodrigo aparece instituido en ejemplo por la vía demostrativa a través de la enumeración de sus acciones, todas ellas en consonancia con los presupuestos iniciales asumidos por el locutor, es decir la instancia de autoridad del discurso. 
El Maestre -locutor 3-, incorpora los argumentos de la Muerte: su aceptación se produce desde la enunciación explícita de lo que sería la tercera potencia del alma - la voluntad-, junto con memoria y entendimiento, convocados en la primera estrofa. Dicha voluntad es enunciada como «plazentera, clara y pura», expresando de este modo la inexistencia de conflicto alguno de instancias. El personaje, por otra parte se dirige a Jesús como garante último que permite resolver el conflicto de la finitud y del paso del tiempo: el mismo garante que desde el principio (IV) había sido convocado por el Locutor en su argumentación. Este último retoma la palabra en la última estrofa, una vez más desde la primera persona del plural: dexónos harto consuelo su memoria. Queda expresada su implicación personal — pertenencia a los próximos del maestre-, al tiempo que de cierta toma de distancia pues no se explicita su condición filial.

En este marco, podemos especificar que la parataxis es una tónica en la composición de la obra, si bien en las primeras estrofas se observa la presencia de conectores que establecen una ilación con la estrofa precedente - II-, los juegos condicionales (II, VI, VII). Y las repeticiones en el inicio de las estrofas, que también juegan como mecanismos de encadenamiento. La presencia explícita de conectores vuelve a observarse a partir de la estrofa XXX: conjunciones copulativas (XXXII), o de conjunciones que expresan una relación causal -XXX-, distributivo-temporal (XXXIII), hasta llegar al encabalgamiento de esta última estrofa sobre la siguiente (XXXIV).

\subsection{Plano del imaginario}

En este punto consideraremos aquellas imágenes que se hallan en la base de la construcción del discurso - podemos observar su correspondencia con los núcleos sobre los que se viene dibujando la progresión argumentativa-, así como de las distintas perspectivas desde las que han sido elaboradas, por otra parte también reflejadas en marcas enunciativas. Una perspectiva rectora dominante - régimen-, que determina el modo particular en que el hombre aprehende el espacio y el tiempo, y por ende a sí mismo y su mundo. Como hemos venido señalando al hilo de los planos anteriores, el poema se construye en torno a dos redes semánticas que generan dos ejes cuya interacción, dilemática, se halla en la base de su progresión, y lo recorre entero: la primera de ellas contrapone el brillo de lo aparente al paso devastador del tiempo; la segunda introduce una atenuación de esa finitud y se impondrá en la segunda parte de la obra.

- Presentación dilemática de dos ejes: Al inicio del poema - I y II- los rostros del tiempo son expresados a través de un juego de superposición temporal, donde el pasado se confunde con el presente y el futuro: el paso del tiempo se sitúa fuera del control del hombre, revelándose una fuerza que lo supera. Chronos devora al tiempo que engendra, destruye las propias creacio- 
nes, agota las fuentes de la vida. Esa aprehensión da lugar desde antiguo a esta visión heracliteana, sustentada sobre el movimiento inexorable del agua —imagen del tiempo- (vida-ríos; morir-mar); para verse posteriormente modificada por otra elaboración de la vida y del mundo, también asociada al tránsito, pero aprehendido como vía hacia una alteridad positiva, figurada desde la imagen del espacio habitable: «morada sin pesar» (V), el espacio de la trascendencia que responde al deseo de pervivencia del sapiens. La figura de Jesús, al que hemos venido señalando como garante en la construcción argumentativa de la obra, funciona como agente mediador entre dos puntos inicialmente planteados desde una relación de exclusión - cielo y tierra; elevación y descenso. Igualmente asociado a la elevación y a la luz, la figura de Jesús, como hombre-Dios que nace-muere-resucita, aparece al final del poema instituido en nexo que hace posible la transformación de la muerte en tránsito. Ambas redes de imágenes coexisten en las estrofas V y VI, lo que les confiere una dimensión dilemática que no hemos dejado de marcar. La primera de ellas, ya apuntada en las estrofas iniciales, se desarrolla entre la estrofa VII — que ya habíamos mostrado como clave en los planos enunciativo y argumentativo-, y la XXIV.

- El brillo de lo fugaz y el paso del tiempo (VII-XXIV). Este juego de imágenes focaliza lo que el Locutor considera una aprehensión del mundo sustentada en una subversión de valores donde lo aparente se impone sobre lo que él considera como la naturaleza profunda de la existencia: la oposición de imágenes «cativa»/»señora»(VII). En este mismo sentido explota la dicotomía ver-no ver, asociada a la de sueño-vigilia ${ }^{7}$. Desde ahí queda establecida una nueva inversión: las imágenes construidas sobre el esquema de la elevación y el esplendor son retomadas desde el movimiento inverso, la caída y la disolución. Abajadas por Fortuna y su rueda, soterradas por la Muerte («cuanto más brillaba fue amatada/ claras hazañas... tú las atierras/ do las escondes»). Estados del mundo particularizados en personajes políticos que se revelan asociados a serie de valores semánticos, todos ellos presentados desde una dinámica de desaparición que suscitaría la pregunta «dónde están», (ubi sunt). Un proceso cuya autoría, en las últimas estrofas de este bloque, es atribuida a la Muerte, personificada e interpelada como hemos visto antes desde el «tú». Esa figuración de la Muerte se completa con una serie de imágenes vinculadas a los instrumentos con los que el héroe épico lucha —armas y fuerzas defensivas, huestes y castillos-, desprovistos en ese momento de eficacia frente el arma (flecha) de la finitud.

- XXV-XL: la reorientación de la dispersión y la finitud: Un segundo decorado es construido a partir de la copla XXV, momento en que el Maes-

\footnotetext{
${ }^{7}$ La Edad Media asocia la ceguera a la falta de consciencia y conciencia, una situación también figurada por la imagen del sueño, o de la locura, tal como ésta es aprehendida en los Libros Sapienciales.
} 
tre es convocado. Entonces constatamos, tal como habíamos avanzado al abordar la configuración argumentativa, la manera en que buena parte de las imágenes consignadas anteriormente experimentan una inversión semántica al estar referidas a él. Se ha producido un cambio de perspectiva, de régimen de la imagen: éstas se agrupan ahora de acuerdo con otras dinámicas adquiriendo de este modo un sentido diferente. El núcleo en torno al cual se construye esta nueva configuración es la figura del Maestre, construida de acuerdo con los rasgos del héroe épico, en su acción conquistadora y fundadora de la tierra, y del tiempo. Particularizado a partir de los rasgos que definen al caballero medieval — valiente, leal y generoso, mostrado desde su desprendimiento con respecto a los bienes materiales y desde su capacidad de combatir a sus oponentes: el tirano y el «otro», en este caso el infiel, todos ellos imágenes de la hybris. En este contexto de la lucha observamos la mención del tablero de ajedrez, una imagen recurrente en discursos medievales — «después de puesta la vida al tablero»—, que se revela imagen del mundo, campo de acción y de batalla, limitado en sus cuatro orientes y definido en su tejido de sombra y luz, evocado por el negro y el blanco. Esta elaboración permite asimilar la acción guerrera del héroe con el combate interno del hombre. Tal es el tenor de las últimas estrofas: la lucha vinculada al tránsito expresado a través de las imágenes de la batalla y el combate. Como habíamos apuntado anteriormente, la tensión de instancias vida-muerte, objetivada a través de las imágenes de la «amarga batalla temerosa»/ «trago» «afruenta», se ve reconducida en una dinámica de armonización: la voluntad es vinculada a imágenes luminosas - clara y pura-, y de calma y placidez (placentera), en oposición al decorado de la batalla anteriormente mostrado. La canalización de la tensión y de las eventuales disonancias tiene además lugar mediante la inscripción del personaje en una concepción temporal liberada de las constricciones del paso del tiempo: una nueva inscripción propiciada por la vía del recuerdo y de la vida eterna. La propia Muerte, ya figurada como personaje, afianza los rasgos que el locutor principal atribuye al Maestre proyectándolos hacia la atemporalidad y hacia «otra vida más larga/de la fama glorïosa/acá dexais» (XXXV), que como ya indicábamos era enunciada por el locutor en la estrofa V. Se produce así la reorientación de la finitud en el espacio de la inmanencia por la vía del recuerdo y la memoria. En cuanto al otro espacio -el trascendente-, el tránsito hacia él es sancionado por la imagen de Jesús, nuevamente invocado por el Maestre como nexo entre lo divino y lo humano. Este último aspecto es evocado desde su aprehensión más negativa en el marco de la oposición elevación/descenso que ya habíamos identificado en la primera parte de la obra: «forma servil y baxo nombre/ cosa tan vil como el hombre». La muerte es así mostrada como vía de transmutación que permite acceder a un estado considerado superior, de modo que su dimensión temible queda definitivamente eliminada. 


\subsection{Plano de la locución}

En este apartado, prestaremos especial atención a la manera en que los movimientos del discurso a los que hemos venido refiriéndonos hasta ahora cobran cuerpo sensible y material.

Considerando su inscripción genérica nuestra obra es una composición poética de tono elegíaco, que inaugura un tipo de estrofa más adelante conocida como manriqueña: la copla de pie quebrado ${ }^{8}$. El arte menor se revela como vía para expresar el ritmo rápido del paso del tiempo y de la situación a la que irremediablemente conduce. Una composición donde actúa especialmente la parataxis, tal como hemos apuntado anteriormente. Dicho paso rápido del tiempo se combina con otro tiempo más pausado, asociado a otro ritmo más constante, más armonioso, más sereno y que viene trazado mediante los lazos, los vínculos, modelados con marcadores, hipotaxis o encabalgamientos, entre unos y otros versos, estrofas y coplas. Clara dimensión sensorial del discurso en verso, cuyo ritmo parece sosegarse a partir de la estrofa XXV — situada por otra parte en mitad de la composición-, momento en que la figura de Don Rodrigo es convocada: la enumeración de hechos y cualidades de personajes diversos, pasa a convertirse en etopeya,de manera que varias estrofas convergen sobre un mismo centro focal. Se advierte en este sentido una mayor presencia de conectores que vinculan explícitamente una estrofa con otra (XXX-XXXIII), hasta llegar al encabalgamiento en el paso de la estrofa XXXIV a la XXXV, momento en que la Muerte es introducida como locutor.

Un locutor que enuncia la mirada que el hombre arroja sobre todo ello, y cómo de esa mirada depende la aprehensión de la muerte, de la vida y del paso del tiempo. Tal sería el tono del exordio, probablemente uno de los más conocidos de la literatura castellana, que marca buena parte del tono de su obra: el imperativo, la exhortación a configurar una perspectiva conveniente sobre la vida (I-II). Los primeros versos convocan, en efecto, al interlocutor, en las primeras estrofas a través del empleo de la tercera persona referida en cada caso a instancias que forman parte de lo humano. La alocución, como ya hemos indicado, se hace progresivamente explícita orientando el discurso sobre la primera persona del plural, para posteriormente, ya en la segunda parte, interpelar al interlocutor de manera directa a través de la segunda persona del plural, dando cuerpo al tema fundamental, la Muerte. Una pregunta cuya

${ }^{8}$ La copla de pie quebrado — manriqueña-, se construye sobre versos octosílabos combinados con tetrasílabos, cuya lectura $-\mathrm{y}$ escucha - nos conduce a reflexionar sobre la corporeidad del discurso construido a partir de los juegos del ritmo y de la rima que implica la poesía. Resulta interesante de hecho comprobar que las escenas enunciativas identificadas en el plano correspondiente, son asociadas a 4 partes: las dos primeras constarían de 12 coplas cada una y de 8 las dos partes siguientes.

Revista de Literatura, 2013, vol. LXXV, n. ${ }^{\circ}$ 149, 15-42, ISSN: 0034-849X, doi: 10.3989/revliteratura.2013.01.002 
repuesta no existe, o por el contrario es demasiado obvia — «dónde están», y que no tiene otro objetivo que suscitar el pathos del interlocutor.

Tras esta interpelación, el locutor explicita, apoyándose en frases de verdad general, una serie de planteamientos sobre el decurso de la vida y la muerte (narratio); para a continuación, y a partir de la convocatoria de personajes históricos presentar las diversas posibilidades de gestionar dicho conflicto, posicionándose frente a ellas y demandando a su interlocutor también una toma de posición. Se produce una acumulación de ejemplos, construidos a partir de una interrogación retórica —ubi sunt- que se repiten generando un efecto de saturación, una amplificación: podríamos hablar de una dinámica digresiva donde se suceden ejemplos vinculados a la historia reciente, que desde una relación de analogía implícita,vienen a confirmar los planteamientos iniciales, y a ilustrar las posibilidades ya apuntadas por la vía de las metáforas. Por un lado se halla el punto de vista adoptado por una gran mayoría: sería el argumento de cantidad, en este caso desvalorizado, en beneficio de un argumento de calidad, atribuido éste al personaje de Don Rodrigo, cuya introducción es el punto de inflexión del razonamiento, cuyo retrato se construye desde una oposición implícita con respecto a los ejemplos anteriores. El texto, como acabamos de apuntar, presenta una tensión a partir de la explotación de la dimensión sensorial del discurso: los juegos de sonidos producidos por la rima, que canalizan la atención sobre los términos clave; la repetición de palabras en la misma estrofa — «allí»(III)/dellas (VIII)—; el juego antitético que preside algunas estrofas, en las que podemos advertir una bipartición. Observamos también cómo las rimas muestran esa inversión en el proceso-XXI (privado/degollado//mandar/dexar)—. O los juegos anafóricos que permiten establecer un encadenamiento deestrofas -Este.../Este (V/VI)// Qué se hizo/qué se hizieron (XVI/XVII); Pues (XVIII/XX/XXI)—. Esta dimensión sensible del discurso está asimismo potenciada en su vertiente «visual» por el juego inicial de sinécdoques, metáforas y símiles que muestran el paso del tiempo desde dos ángulos distintos, y desde donde arranca una antítesis, que contrapone las dos redes de sentido creadas por las imágenes a las que acabamos de referirnos: lo pasajero vinculado a la idea de desaparición (metáforas de la finitud) y lo pasajero vinculado a una meta instituida como definitiva (metáforas del tránsito).

Este proceso de imaginación de cuyo funcionamiento hemos dado cuenta, culmina con la personificación de la Muerte, que permite escenificar un diálogo entre ella y el caballero. Este recurso la hace presente de modo inmediato en el discurso, y no sólo atenúa su vertiente destructiva, sino que permite, mediante la interacción respetuosa que establece con el Maestre, la construcción de este último en la «fisicidad» de un discurso donde él mismo manifiesta la superación de la angustia que produce el final de la vida.

Es ésta la conclusión a la que conduce el proceso de demostración, en cuyo transcurso don Rodrigo es situado en una relación de oposición a los ejemplos 
mostrados en los últimos versos, pero en sintonía con los argumentos esbozados en las primeras estrofas, construidos de acuerdo con un garante argumental que se identifica con un principio trascendente y absoluto - Jesús.

Tras un juego retórico que muestra puntos de vista encontrados, el personaje central es configurado desde una dinámica de antífrasis: como ya hemos indicado al acercarnos a los planos de la argumentación y de la imagen, se produce una atenuación de la dimensión negativa anteriormente conferida al paso del tiempo. Asimismo podríamos entrever una suerte de retractación por parte del locutor principal que para el retrato del Maestre se sirve de recursos discursivos anteriormente rechazados - las antonomasias formadas a partir de personajes de la Antigüedad. Tras ello el mismo locutor en su peroratio sanciona la pervivencia del Maestre, desde una implicación explícita con su figura — «dejonos harto consuelo su memoria», mediante el uso de la primera persona del plural.Ahora bien, sólo el paratexto — «Coplas a la muerte de su padre»- lo identifica desde una relación filial. Desde esa inscripción/ implicación el locutor construye el ethos del personaje principal, oponiéndolo a una configuración que funciona como anti-ejemplo, y de la que ya hemos venido dando amplia cuenta.

\subsection{Plano de la topicalidad}

En el plano de la topicalidad detectamos una actuación intersubjetiva que se desarrolla desde una recuperación de imágenes y una inserción enunciativa, argumentativa y locutiva: el discurso se desarrolla marcado por actitudes como los afectos, el conocimiento, la voluntad, el desarrollo, transcendidos por la experiencia de «la muerte» de «su» padre. Las Coplas ofrecen un acceso a principios fundamentales de conocimiento, social o individual, público o privado, y a principios comunes que trascienden el discurso a modo de guiones discursivos. En este sentido podemos citar: la muerte y la vida, el ser humano, desarrollados en el despliegue de una escala donde se advierte una confrontación de perspectivas y de opciones, resueltas por parte del Locutor mediante un punto de fuga asociado con lo Absoluto. La finitud de la vida es filtrada a través de la cosmovisión cristiana como transitoria; sin embargo nuestro autor - al igual que otros autores próximos a él en el espacio y en el tiempo-, no deja de llamar la atención sobre la dispersión hacia otros centros, móviles e inestables, subrayando la negatividad de esta opción. Para ello se sirve de motivos, situaciones y topoï que, resultado de esa figuración de la lucha del hombre contra la finitud, han ido formando parte de la historia de las ideas y de la estética: el contemptu mundi, el ubi sunt que ya se identifica en la Biblia, en los autores clásicos y del Medievo. Lugares comunes que reconocemos en obras literarias del siglo XIV y XV, un momento en que el motivo de la muerte se hace omnipresente, así como el tema de Fortuna, 
que a lo largo de la Edad Media va dejando sentir su presencia en el discurso filosófico, literario y en las obras plásticas. A partir de estos motivos, la voz del locutor alerta sobre la condición fugaz del tiempo y la naturaleza de Homo Viator del ser humano.

Siguiendo las pautas que avanzábamos en los otros planos, hemos tratado de reconocer y mostrar los mecanismos que crean esos efectos particulares capaces de interpelar al hombre hasta el punto de que éste pueda hacerlo suyo. Identificarlos, acercarnos a sus orígenes, y además determinar la interacción de unos lugares con otros que en cada caso se produce: en la obra de Manrique la muerte asociada con la finitud se opone la vida como tránsito. Estableciendo una correspondencia progresiva con cada uno de estos tópicos se contraponen respectivamente las, también distintas, actitudes del hombre frente a ello: ceguera-locura//mirada lúcida-sensatez. Este proyecto discursivo muestra cómo es esta última opción la que se impone, mediante un juego de inversiones que disuelve la tensión inicial.

Sin haber agotado las posibilidades de análisis, este recorrido por las Coplas ha tratado de ser la ilustración de una propuesta de trabajo que permite acceder al trazado de una obra combinando la atención al detalle de los distintos fenómenos discursivos, con su inscripción dentro de una perspectiva de globalidad, que podría incluso extenderse más allá de la propia obra en cuestión.

\section{BIBLIOGRAFÍA CITADA}

Ducrot, Oswald (1984a). Le dire et le dit. Paris: Les Éditions de Minuit.

Ducrot, Oswald (1984b). L'argumentation dans la Langue. Paris: Mardaga.

Durand, Gilbert (1969). Les structures anthropologiques de l'imaginaire. Paris: PUF.

Durand, Gilbert (1996). Champs de l'Imaginaire Grenoble: ELLUG.

Forget, Danielle (2000). Figures de pensée, figures du discours. Québec: Nota Bene.

García Berrio, Antonio (1994). Teoría de la Literatura. La construcción del significado. Madrid: Ediciones Cátedra (1 1989$)$.

García Negroni, M. y Marta Tordesillas (2001). La enunciación en la lengua. De la deixis a la polifonía. Madrid: Gredos.

Garrido Gallardo, Miguel Ángel (1994). La musa de la Retórica. Madrid: CSIC(2a edic. ampliada de Estudios de Semiótica Literaria, 1982).

Garrido Gallardo, Miguel Ángel (2010). Nueva Introducción a la Teoría de la Literatura. Madrid: Síntesis. ( $1^{\mathrm{a}}$ edic. 2000$)$.

Manrique, Jorge (1992). Poesía, ed. Jesús-Manuel Alda Tesán. Madrid: Cátedra.

Manrique, Jorge (1993). Poesía, ed. Vicente Beltrán. Barcelona: Crítica.

Manrique, Jorge (2000). Poesía completa, ed. Ángel Gómez Moreno. Madrid: Alianza.

Manrique, Jorge (2003). Poesía, ed. María Morrás. Madrid, Castalia.

Moeschler, J. y A.M. Reboul (1998). Pragmatique du discours: de l'interprétation de l'énoncé à l'interprétation du discours. Paris: Armand Colin.

Prado Biezma, J. del (2004). Análisis e interpretación de la Novela. Madrid: Síntesis.

Suárez, María-Pilar (1998). «La mère et la femme fatale chez Villon», Bien dire et bien aprandre. Centre d'Etudes Médiévales de Lille III. V. 16, pp. 237-245. 
Suárez, María-Pilar (2002). «La literatura de combate», en Boixareu, M; Lefere, R (eds.), La Historia de España en la Literatura Francesa. Madrid: Castalia, pp. 181-198.

Suárez, María-Pilar (2004). «Christine de Pizane et la reconnaissance de la mère». Revue des Lettres et de Traduction. V. 10, pp.285-301.

Suárez, María-Pilar (2007). «Le personnage du juif et l'énonciation de l'hétérogène», en Connochie-Bourgne, Chantal, (éd), Façonner son personnage au Moyen Age. Aix-enProvence: Université de Provence I, pp. 309-318.

Suárez, María-Pila (2010). «Le Jeu de Robin et Marion. Une approche intersémiotique», en Salvan, G. (éd.), Ci-Dit. Discours rapporté, citation et pratiques sémiotique. Nice: Université de Nice, pp. 323-339.

Suárez, María-Pilar (2012). «Effets de style, effets de sens», en Connochie, Ch. y Douchet, S. (éds), Effets de style. Aix-en-Provence, Université de Marseille, pp. 351-362.

Tordesillas, Marta (1997). «De la gradualité dans la langue au degré d'implication du locuteur», Cuadernos de Filología Francesa. N. ${ }^{\circ}$ 9, pp. 135-149.

Tordesillas, Marta (1998). «Esbozo de una teoría dinámica de la lengua en el marco de una semántica argumentativa», Signo y Seña $n^{\circ}$ 9, pp.349-378.

Tordesillas, Marta (1998). «De la Gramática al Discurso. De la coordinación y la subordinación al concepto de dinámica discursiva», Discurso $n .^{\circ}$ 21/22, pp.167-183.

Tordesillas, Marta (2004). «Los planos del discurso. Fundamentos teóricos para una nueva semántica». Actas I del VIII Simposio Internacional de Comunicación Social. Cuba: Centro de Lingüística Aplicada.

Tordesillas, Marta (2005). "Connecteurs et configuration sémantique/pragmatique : une histoire de point de vue», Signes, Langues et cognition. Paris: L’Harmattan, pp.135-149.

Tordesillas, Marta (2007). «La enunciación: fundamentos de lenguaje, principios de lengua, perspectiva docente», en Vera Sant'Anna y Bruno Deusdara, Trajetórias em Enunciaçiao e Discurso, conceitos e práticas. Río de Janeiro: Clara Luz Editora, pp. 122-144.

Tordesillas, Marta (2008). «À propos du signe linguistique: énonciation, argumentation et stéréotype», en El valor de la diversidad. Madrid: U.A.M.

Yllera, A. (1974). Estilística, poética y semiótica literaria. Madrid: Alianza

Yllera, A. (1999). Teoría de la Literatura Francesa. Madrid: Síntesis.

Fecha de recepción: 23 de julio de 2010

Fecha de aceptación: 25 de enero de 2011 